\title{
An Economic Growth Model with Optimal Growth Rate and Individual Years of Schooling
}

\author{
Huan Yang, ${ }^{1}$ Donghan Cai, ${ }^{1}$ and Zhongbin Chen ${ }^{2}$ \\ ${ }^{1}$ College of Mathematics and Statistics, Wuhan University, Wuhan 430072, China \\ ${ }^{2}$ School of Economics and Management, Wuhan University, Wuhan 430072, China \\ Correspondence should be addressed to Donghan Cai; dhcai@whu.edu.cn
}

Received 18 April 2015; Accepted 16 June 2015

Academic Editor: Luca Gori

Copyright (c) 2015 Huan Yang et al. This is an open access article distributed under the Creative Commons Attribution License, which permits unrestricted use, distribution, and reproduction in any medium, provided the original work is properly cited.

An economic growth model with individual years of schooling is present. It is proved that there exist optimal individual years of schooling for fixed wage growth rate. On the other hand, the economy has balance growth path for given individual years of schooling. Finally, we prove that there exist optimal individual years of schooling and economic growth rate such that the individual lifetime utility reaches maximum and the economy grows on a balance growth path.

\section{Introduction}

The relationship between economic growth and education has been deeply researched by economists. Barro and many others [1-3] found that educational level is positively correlated with the growth rate of per capita GDP across countries. On the other hand, the empirical analysis [4-6] showed that the individual years of schooling increase with the economic growth and the individual earnings are positively related to years of schooling.

In [7], Kalemli-Ozcan et al. used a continuous overlapping generations model to inquire individual optimal schooling investment choices and argued that mortality decline produces economically significant increases in schooling and consumption. In their model, the longevity of individual is infinite, and the retirement age and the relationship between schooling and economic growth are not considered.

Futagami and Nakajima [8] used a general equilibrium model in which individual has finite longevity and the retirement age is considered to show that population aging is not necessarily a negative factor for economic growth. However, their paper did not involve individual years of schooling.

In this paper, the individual years of schooling are integrated into the analysis framework provided by Futagami and Nakajima to inquire the relationship between the economic growth and the individual years of schooling. It is firstly proved that there exist optimal years of schooling for the individual such that the individual lifetime utility reaches maximum under the fixed wage growth rate. Then, the connection between wages and economic growth rate are obtained by using the aggregate economic balance condition $\dot{K}=Y-C$ and the existence that the economy has balance growth path is proved for given individual years of schooling. Finally, we show that under certain conditions there exist optimal individual years of schooling and an economic growth rate such that the individual utility reaches maximum and the economy grows on the balance growth path.

The paper is organized as follows. The problem of the individual optimal consumption and years of schooling are discussed in Section 2 and the existence of the balance growth path is studied in Section 3. In Section 4, the proof of the economy has the optimal individual years of schooling and balance economic growth rate such that the economy balanced growth is presented and the conclusions are given in Section 5.

\section{The Optimal Consumption and Individual Years of Schooling}

2.1. The Individual Optimal Problem. For simplification, we follow the assumption given by Futagami and Nakajima [8] that the individual is completely foresighted and knows his biological maximum lifespan $\Omega$. Denote the consumption, 
asset, and wage of individual born at time $b$ by $c(b, t), a(b, t)$, and $w\left(t, T_{1}\right)$ at time $t$, respectively.

The individual begins to work after ending his schooling at age $T_{1}$ until he retires at age $T_{2}\left(0<T_{1}<T_{2}<\Omega\right)$ and inelastically supplies one unit of labor. Following KalemliOzcan et al. [7], the real earnings of an individual who ended schooling at age $T_{1}$ and works at time $t\left(b+T_{1} \leq t \leq t+T_{2}\right)$ are $\widetilde{w}(t) g\left(T_{1}\right)$, where $\widetilde{w}(t)$ is the wage per unit of human capital and $g\left(T_{1}\right)$ is the individual quantity of human capital got from $T_{1}$ years of schooling. Assume that the individual who has no education has unit of human capital and the individual's quantity of human capital increases with the years of schooling; that is, the function $g\left(T_{1}\right)$ satisfies $g(0)=1$ and $g^{\prime}(\cdot)>0$. Hence the lifetime earnings of an individual satisfy

$$
w\left(t, T_{1}\right)= \begin{cases}0, & b \leq t<b+T_{1}, \\ \widetilde{w}(t) g\left(T_{1}\right), & b+T_{1} \leq t \leq b+T_{2}, \\ 0, & b+T_{2}<t \leq b+\Omega .\end{cases}
$$

Following the assumption used by Blanchard [9], d'Albis [10], and Futagami and Nakajima [8], we assume that individual is nonaltruistic and has no bequest motives, which implies he or she would use up all his or her assets when he or she died and would leave no asset to his or her offspring. Therefore, the individual has no asset when he or she was born and when he or she died. That is,

$$
a(b, b)=a(b, b+\Omega)=0,
$$

and the individual budget constraint is

$$
\dot{a}(b, t)=r(t) a(b, t)+w\left(t, T_{1}\right)-c(b, t) .
$$

The lifetime utility of the individual born at time $b$ is

$$
\int_{b}^{b+\Omega} e^{-\rho(t-b)} \frac{c(b, t)^{1-1 / \sigma}-1}{1-1 / \sigma} d t
$$

where $\rho$ stands for the rate of time preference and $r(t)$ is the real interest rate, $\left(c(b, t)^{1-1 / \sigma}-1\right) /(1-1 / \sigma)$ is the instantaneous utility, and the elasticity of substitution for this utility function is $1 / \sigma$.

The individual optimal problem is to maximize (4) subject to (1)-(3).

2.2. The First Order Condition. The current value Hamiltonian to solve the optimization problem of individuals is

$$
\begin{aligned}
H(t, a, c)= & e^{-\rho(t-b)} \frac{c(b, t)^{1-1 / \sigma}-1}{1-1 / \sigma} \\
& +\lambda(t)\left[r(t) a(b, t)+w\left(t, T_{1}\right)-c(b, t)\right]
\end{aligned}
$$

and the optimal condition and multiply equation are

$$
\begin{aligned}
0 & =\frac{\partial H}{\partial c}=e^{-\rho(t-b)} c(b, t)^{-1 / \sigma}-\lambda(t), \\
\dot{\lambda}(t) & =-\frac{\partial H}{\partial a}=-\lambda(t) r(t) .
\end{aligned}
$$

2.3. Optimal Consumption Path of Individuals. By (6),

$$
\begin{aligned}
r(t) & e^{-\rho(t-b)} c(b, t)^{-1 / \sigma} \\
= & \rho e^{-\rho(t-b)} c(b, t)^{-1 / \sigma} \\
& +\frac{1}{\sigma} e^{-\rho(t-b)} c(b, t)^{-1 / \sigma-1} \dot{c}(b, t) ;
\end{aligned}
$$

that is, $\dot{c}(b, t) / c(b, t)=\sigma(r(t)-\rho)$. Integrating the above equation on both sides, we obtain

$$
c(b, t)=c(b, b) e^{\int_{b}^{t} \sigma(r(\tau)-\rho) d \tau} .
$$

$\Omega$,

Multiplying (3) by $e^{-\int_{b}^{t} r(\tau) d \tau}$ and integrating from $b$ to $b+$

$$
\begin{aligned}
\int_{b}^{b+\Omega} & \frac{\partial e^{-\int_{b}^{t} r(\tau) d \tau} a(b, t)}{\partial t} d t \\
= & \int_{b}^{b+\Omega} w\left(t, T_{1}\right) e^{-\int_{b}^{t} r(\tau) d \tau} d t \\
& -\int_{b}^{b+\Omega} c(b, t) e^{-\int_{b}^{t} r(\tau) d \tau} d t .
\end{aligned}
$$

From (1) and (2),

$$
\begin{aligned}
0= & \left.e^{-\int_{b}^{t} r(\tau) d \tau} a(b, t)\right|_{b} ^{b+\Omega} \\
= & g\left(T_{1}\right) \int_{b+T 1}^{b+T_{2}} \widetilde{w}(t) e^{-\int_{b}^{t} r(\tau) d \tau} d t \\
& -\int_{b}^{b+\Omega} c(b, t) e^{-\int_{b}^{t} r(\tau) d \tau} d t .
\end{aligned}
$$

Substituting (8) into the last term of the above equality, we have

$$
\begin{aligned}
& g\left(T_{1}\right) \int_{b+T_{1}}^{b+T_{2}} \widetilde{w}(t) e^{-\int_{b}^{t} r(\tau) d \tau} d t \\
& \quad=c(b, b) \int_{b}^{b+\Omega} e^{\int_{b}^{t}[(\sigma-1) r(\tau)-\sigma \rho] d \tau} d t .
\end{aligned}
$$

So,

$$
c(b, b)=\frac{g\left(T_{1}\right) \int_{b+T_{1}}^{b+T_{2}} \widetilde{w}(t) e^{-\int_{b}^{t} r(\tau) d \tau} d t}{\int_{b}^{b+\Omega} e^{\int_{b}^{t}[(\sigma-1) r(\tau)-\sigma \rho] d \tau} d t} .
$$

From (8) and (12), we have the following theorem.

Theorem 1. The optimal consumption path of individuals is

$$
c(b, t)=\frac{g\left(T_{1}\right) \int_{b+T_{1}}^{b+T_{2}} \widetilde{w}(t) e^{-\int_{b}^{t} r(\tau) d \tau} d t}{\int_{b}^{b+\Omega} e^{\int_{b}^{t}[(\sigma-1) r(\tau)-\sigma \rho] d \tau} d t} e^{\int_{b}^{t} \sigma(r(\tau)-\rho) d \tau} .
$$


Corollary 2. If the interest is fixed $r$ and the wage growth rate $\dot{\widetilde{w}}(t) / \widetilde{w}(t)$ is $\gamma$, the individual optimal consumption path is given by

$$
\begin{aligned}
& c(b, t) \\
& =\frac{g\left(T_{1}\right) \widetilde{w}\left(b+T_{1}\right) \int_{T_{1}}^{T_{2}} e^{(\gamma-r) u} d u}{\int_{0}^{\Omega} e^{[(\sigma-1) r-\sigma \rho] u} d u} e^{\sigma(r-\rho)(t-b)-\gamma T_{1}} .
\end{aligned}
$$

Proof. For a fixed interest rate $r, \dot{\vec{w}}(t) / \widetilde{w}(t)=\gamma$ and $\widetilde{w}(u+b)=$ $\widetilde{w}\left(b+T_{1}\right) e^{\gamma\left(u-T_{1}\right)}$. So,

$$
\begin{aligned}
c(b, b) & =\frac{g\left(T_{1}\right) \int_{b+T 1}^{b+T_{2}} \widetilde{w}(t) e^{-r(t-b)} d t}{\int_{b}^{b+\Omega} e^{[(\sigma-1) r(\tau)-\sigma \rho](t-b)} d t} \\
& =\frac{g\left(T_{1}\right) \int_{T_{1}}^{T_{2}} \widetilde{w}(u+b) e^{-r u} d u}{\int_{0}^{\Omega} e^{[(\sigma-1) r(\tau)-\sigma \rho] u} d u} .
\end{aligned}
$$

The corollary holds.

\subsection{Optimal Individual Years of Schooling}

Theorem 3. If $g\left(T_{1}\right)$ grows at rate $\eta$, for any fixed $\gamma$, the optimal years of schooling are $T_{1}=T_{2}-(\ln (1+(\gamma-r) / \eta)) /(\gamma-$ $r)\left(0<r-\eta<\gamma<r, T_{2}>1 / \eta\right)$.

Proof. Let

$$
Q\left(T_{1}\right)=g\left(T_{1}\right) \int_{b+T_{1}}^{b+T_{2}} \widetilde{w}(t) e^{-r(t-b)} d t
$$

then the necessary and sufficient condition for the individual achieving his maximal consumption is given by

$$
\begin{aligned}
\frac{d Q\left(T_{1}\right)}{d T_{1}}= & g^{\prime}\left(T_{1}\right) \int_{b+T_{1}}^{b+T_{2}} \widetilde{w}(t) e^{-r(t-b)} d t \\
& -g\left(T_{1}\right) \widetilde{w}\left(b+T_{1}\right) e^{-r T_{1}}=0 .
\end{aligned}
$$

Since $\int_{b+T_{1}}^{b+T_{2}} \widetilde{w}(t) e^{-r(t-b)} d t=\widetilde{w}\left(b+T_{1}\right) e^{-\gamma T_{1}} \int_{T_{1}}^{T_{2}} e^{(\gamma-r) u} d u, \eta=$ $g^{\prime}\left(T_{1}\right) / g\left(T_{1}\right)=e^{(\gamma-r) T_{1}} / \int_{T_{1}}^{T_{2}} e^{(\gamma-r) u} d u$; that is,

$$
\eta=\frac{e^{(\gamma-r) T_{1}}}{\int_{T_{1}}^{T_{2}} e^{(\gamma-r) u} d u}
$$

From (18), we have

$$
\begin{aligned}
& T_{1}=T_{2}-\frac{\ln (1+(\gamma-r) / \eta)}{\gamma-r} \\
& \quad\left(0<r-\eta<\gamma<r, T_{2}>\frac{1}{\eta}\right) .
\end{aligned}
$$

Corollary 4. The optimal individual years of schooling increase strictly with respect to wage growth rate; that is, $T_{1}=$ $T_{1}(\gamma)$ and $d T_{1}(\gamma) / d \gamma>0$.

Proof. By (19), $T_{1}(\gamma)=T_{2}-(\ln (1+(\gamma-r) / \eta)) /(\gamma-r)(0<$ $\left.r-\eta<\gamma<r, T_{2}>1 / \eta\right)$. Let

$$
N\left(\gamma, T_{1}\right)=\frac{e^{(\gamma-r) T_{1}}}{\int_{T_{1}}^{T_{2}} e^{(\gamma-r) u} d u}-\eta ;
$$

then

$$
\begin{aligned}
& \frac{\partial N\left(\gamma, T_{1}\right)}{\partial \gamma}=\frac{e^{(\gamma-r) T_{1}} \int_{T_{1}}^{T_{2}}\left(T_{1}-u\right) e^{(\gamma-r) u} d u}{\left[\int_{T_{1}}^{T_{2}} e^{(\gamma-r) u} d u\right]^{2}}<0, \\
& \frac{\partial N\left(\gamma, T_{1}\right)}{\partial T_{1}}=\frac{e^{(\gamma-r)\left(T_{1}+T_{2}\right)}}{\left[\int_{T_{1}}^{T_{2}} e^{(\gamma-r) u} d u\right]^{2}}>0 .
\end{aligned}
$$

Therefore, $d T_{1}(\gamma) / d \gamma=-(\partial N / \partial \gamma) /\left(\partial N / \partial T_{1}\right)>0$ and the corollary holds.

\section{The Balance Growth Path}

3.1. Accumulate Consumption and Production Function. Following Futagami and Nakajima [8], it is supposed that the number of households $N$ is constant. Since the lifespan of individuals is $\Omega$, therefore the aggregate consumption $C(t)$ at time $t$ is given by

$$
C(t)=\int_{t-\Omega}^{t} \frac{N}{\Omega} c(b, t) d b .
$$

Following Romer [11] and others, the production function of a perfectly competitive firm $i$ is assumed as follows:

$$
Y_{i}=A K_{i}^{1-\alpha}\left(h\left(T_{1}\right) L_{i} \bar{K}\right)^{\alpha},
$$

where $Y_{i}, K_{i}$, and $L_{i}$ are the output, capital, and employed labor of firm's $i . K$ is total capital and $h\left(T_{1}\right)$ is knowledge. Consider $\bar{K} \equiv K / h\left(T_{1}\right) L$ and $L$ is constant labor supply given by

$$
L=\int_{t-T_{2}}^{t-T_{1}}\left(\frac{N}{\Omega}\right) d \tau=\frac{N\left(T_{2}-T_{1}\right)}{\Omega} .
$$

Notice that profit maximization firm's behaviour satisfies the following two conditions in perfectly competitive market: its marginal product of capital equals the real interest rate and its marginal product of labor equals the real wage rate; that is,

$$
\begin{aligned}
r & =A(1-\alpha) K_{i}^{-\alpha}\left[h\left(T_{1}\right) L_{i} \bar{K}\right]^{\alpha}, \\
\widetilde{w}(t) g\left(T_{1}\right) & =\frac{\alpha A K_{i}^{1-\alpha}\left[h\left(T_{1}\right) L_{i} \bar{K}\right]^{\alpha}}{L_{i}}=\frac{\alpha Y_{i}}{L_{i}} .
\end{aligned}
$$


3.2. The Existence of Balance Economic Growth Rate. It is assumed as Futagami and Nakajima [8] that the capital labor ratio is equalized across firms; that is, $K_{i} / h\left(T_{1}\right) L_{i}=$ $K / h\left(T_{1}\right) L$. So we can obtain the following lemma.

Lemma 5. The wage rate grows at the same rate as total output and total physical capital; that is, $\dot{Y} / Y=\dot{K} / K=\dot{\tilde{w}} / \widetilde{w}=\gamma$.

Proof. From $K_{i} / h\left(T_{1}\right) L_{i}=K / h\left(T_{1}\right) L$ and (23), we have

$$
Y_{i}=A K_{i}^{1-\alpha}\left[h\left(T_{1}\right) L_{i} \frac{K_{i}}{h\left(T_{1}\right) L_{i}}\right]^{\alpha}=A K_{i} .
$$

Therefore,

$$
Y=A K
$$

By (25),

$$
\begin{aligned}
r & =A(1-\alpha), \\
\widetilde{w}(t) g\left(T_{1}\right) & =\frac{\alpha Y}{L} .
\end{aligned}
$$

So, $Y, K$, and $\widetilde{w}$ have the same growth rate and the lemma holds.

Substituting (14) and (24) into (22), we obtain

$$
\begin{aligned}
C(t)= & \frac{L}{T_{2}-T_{1}} \frac{g\left(T_{1}\right) \int_{T_{1}}^{T_{2}} e^{(\gamma-r) u} d u}{\int_{0}^{\Omega} e^{[(\sigma-1) r-\sigma \rho] u} d u} \\
& \cdot \int_{t-\Omega}^{t} \widetilde{w}\left(b+T_{1}\right) e^{\sigma(r-\rho)(t-b)-\gamma T_{1}} d b .
\end{aligned}
$$

From

$$
\begin{gathered}
\int_{t-\Omega}^{t} \widetilde{w}\left(b+T_{1}\right) e^{\sigma(r-\rho)(t-b)-\gamma T_{1}} d b \\
=\int_{0}^{\Omega} \widetilde{w}(t) e^{[\sigma(r-\rho)-\gamma] v} d v
\end{gathered}
$$

the aggregate consumption $C(t)$ turns into

$$
C(t)=\operatorname{Lg}\left(T_{1}\right) \widetilde{w}(t) D\left(\gamma, T_{1}\right),
$$

where

$$
D\left(\gamma, T_{1}\right)=\frac{\int_{T_{1}}^{T_{2}} e^{(\gamma-r) u} d u \int_{0}^{\Omega} e^{[\sigma(r-\rho)-\gamma] v} d v}{\left(T_{2}-T_{1}\right) \int_{0}^{\Omega} e^{[(\sigma-1) r-\sigma \rho] u} d u}
$$

If we do not consider depreciation, the equilibrium condition in the output market is $\dot{K}=Y-C$ and from this condition we have the following theorem.

Theorem 6. The balance economic growth rate is determined by the equation $\gamma=A S\left(\gamma, T_{1}\right)$, where $S\left(\gamma, T_{1}\right)=1-\alpha D\left(\gamma, T_{1}\right)$.
Proof. From (27) and (29), we have

$$
K=\frac{\widetilde{w}(t) g\left(T_{1}\right) L}{\alpha A}
$$

using (29), (32), and (34), we can rewrite $\dot{K}=Y-C$ as

$$
\gamma=A\left[1-\alpha D\left(\gamma, T_{1}\right)\right]
$$

Theorem 7. If $S\left(0, T_{1}\right)<0$ and $\left.A\left(\partial S\left(\gamma, T_{1}\right) / \partial \gamma\right)\right|_{\gamma=r}<1$, then the balance growth rate $\gamma$ is existent and unique for any given years of schooling $T_{1} \in\left(0, T_{2}\right)$.

Proof. Let $F\left(\gamma, T_{1}\right)=A S\left(\gamma, T_{1}\right)$; then, from

$$
\begin{aligned}
& \frac{\partial^{2} F\left(\gamma, T_{1}\right)}{\partial \gamma^{2}} \\
& \quad=-\frac{\alpha A \int_{T_{1}}^{T_{2}} \int_{0}^{\Omega}(u-v)^{2} e^{(\gamma-r) u} e^{[\sigma(r-\rho)-\gamma] v} d u d v}{\left(T_{2}-T_{1}\right) \int_{0}^{\Omega} e^{[(\sigma-1) r-\sigma \rho] u} d u}<0,
\end{aligned}
$$

$F\left(\gamma, T_{1}\right)$ is a concave function.

For $\left.D\left(\gamma, T_{1}\right)\right|_{\gamma=r}=1,\left.F\left(\gamma, T_{1}\right)\right|_{\gamma=r}=\gamma$. So, $F\left(\gamma, T_{1}\right)$ and a 45-degree line have an intersection $\gamma=r$. Since $S\left(0, T_{1}\right)<0$ and $\left.A\left(\partial S\left(\gamma, T_{1}\right) / \partial \gamma\right)\right|_{\gamma=r}<1$, the curve $F\left(\gamma, T_{1}\right)$ and a $45-$ degree line have another intersection which is the balance growth rate, as shown in Figure 1. At the intersection $E_{2}$, the stock market is not equilibrated [8]; therefore only at the intersection $E_{1}$, the growth rate is the balance economic growth rate, in which $\gamma<r$.

Remark 8. The assumption $S\left(0, T_{1}\right)<0$ holds when $r$ is larger enough than $\rho$ and $\sigma=1$.

In fact, $S\left(0, T_{1}\right)=1-\alpha \int_{T_{1}}^{T_{2}} e^{-r u} d u \int_{0}^{\Omega} e^{\sigma(r-\rho) v} d v /\left(T_{2}-\right.$ $\left.T_{1}\right) \int_{0}^{\Omega} e^{[(\sigma-1) r-\sigma \rho] u} d u$.

Let $B\left(T_{1}\right)=\int_{T_{1}}^{T_{2}} e^{-r u} d u /\left(T_{2}-T_{1}\right)$; then

$$
\frac{\partial B\left(T_{1}\right)}{\partial T_{1}}=\frac{\int_{T_{1}}^{T_{2}}\left[e^{-r u}-e^{-r T_{1}}\right] d u}{\left(T_{2}-T_{1}\right)^{2}}<0
$$

and $\lim _{T_{1} \rightarrow T_{2}} B\left(T_{1}\right)=e^{-r T_{2}}$. So, $\lim _{T_{1} \rightarrow T_{2}} \alpha D\left(0 ; T_{1}\right)=$ $\alpha e^{-r T_{2}} \int_{0}^{\Omega} e^{\sigma(r-\rho) v} d v / \int_{0}^{\Omega} e^{[(\sigma-1) r-\sigma \rho] u} d u$.

When $\sigma=1, \int_{0}^{\Omega} e^{[(\sigma-1) r-\sigma \rho] u} d u=\int_{0}^{\Omega} e^{-\rho u} d u<\Omega$. If $r$ is larger enough than $\rho$, then $\alpha e^{-r T_{2}} \int_{0}^{\Omega} e^{\sigma(r-\rho) v} d v>$ $\alpha \int_{T_{2}}^{\Omega} e^{(r-\rho) v-r T_{2}} d v>\Omega$ which ensures that $S\left(0, T_{1}\right)<1-$ $\alpha e^{-r T_{2}} \int_{0}^{\Omega} e^{\sigma(r-\rho) v} d v / \int_{0}^{\Omega} e^{[(\sigma-1) r-\sigma \rho] u} d u<0$.

When the parameters are taken the values $\alpha=2 / 3, r=$ $0.2, T_{2}=60, \Omega=100, \rho=0.05, \sigma=1$, and $S\left(0, T_{1}\right)<$ $1-\alpha e^{-r T_{2}} \int_{0}^{\Omega} e^{\sigma(r-\rho) v} d v / \int_{0}^{\Omega} e^{[(\sigma-1) r-\sigma \rho] u} d u \approx-3.49<0$. 


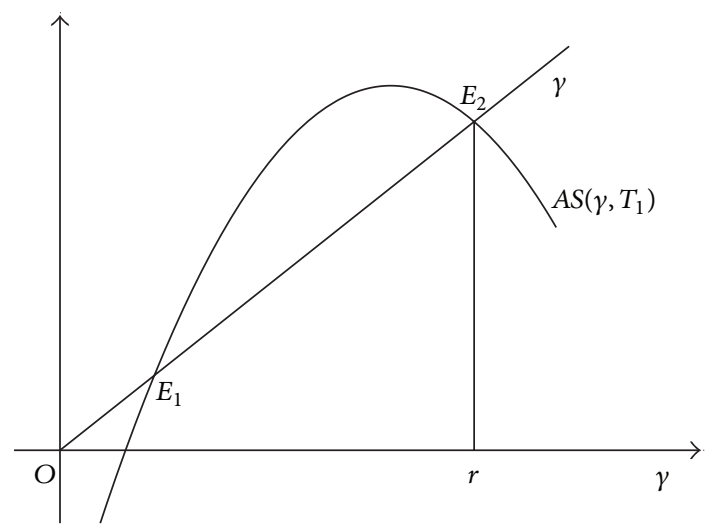

FIgURE 1: The intersection of curve $A S\left(\gamma, T_{1}\right)$ and 45-degree line.

Remark 9. If $T_{2}$ is larger enough than $1 / \rho$ and $\sigma=1$, the assumption $\left.A\left(\partial S\left(\gamma, T_{1}\right) / \partial \gamma\right)\right|_{\gamma=r}<1$ holds.

In fact, by

$$
\begin{gathered}
\left.A \frac{\partial S\left(\gamma, T_{1}\right)}{\partial \gamma}\right|_{\gamma=r} \\
=A \alpha\left(\frac{\int_{0}^{\Omega} u e^{[(\sigma-1) r-\sigma \rho] u} d u}{\int_{0}^{\Omega} e^{[(\sigma-1) r-\sigma \rho] v} d v}-\frac{T_{1}+T_{2}}{2}\right), \\
\left.A \frac{\partial S\left(\gamma, T_{1}\right)}{\partial \gamma}\right|_{\gamma=r}=A \alpha\left(\frac{\int_{0}^{\Omega} u e^{-\rho u} d u}{\int_{0}^{\Omega} e^{-\rho u} d u}-\frac{T_{1}+T_{2}}{2}\right) \\
<A \alpha\left(\frac{\int_{0}^{\Omega} u e^{-\rho u} d u}{\int_{0}^{\Omega} e^{-\rho u} d u}-\frac{T_{2}}{2}\right),
\end{gathered}
$$

when $\sigma=1$.

If $T_{2} / 2>1 / \rho$, then

$$
\begin{aligned}
A \alpha & \left(\frac{\int_{0}^{\Omega} u e^{-\rho u} d u}{\int_{0}^{\Omega} e^{-\rho u} d u}-\frac{T_{2}}{2}\right) \\
& =A \alpha\left(\frac{1}{\rho}+\frac{\Omega e^{-\rho \Omega}}{e^{-\rho \Omega}-1}-\frac{T_{2}}{2}\right)<0<1 .
\end{aligned}
$$

So, $\left.A\left(\partial S\left(\gamma, T_{1}\right) / \partial \gamma\right)\right|_{\gamma=r}<1$.

When the above parameters are taken the values $\rho=0.05$ and $T_{2}=60$ and the condition $T_{2} / 2>1 / \rho$ holds.

\section{The Optimal Individual Years of Schooling and Balance Economic Growth}

In this section, we inquire whether we can find the optimal individual years of schooling and an economic growth rate, such that individual lifetime utility reaches maximum and the growth of economy is balanced.
Lemma 10. At steady state, the years of schooling decrease strictly with respect to wage growth rate; that is, $T_{1}=\widetilde{T}_{1}(\gamma)$ and $d \widetilde{T}_{1}(\gamma) / d \gamma<0$.

Proof. Let

$$
G\left(\gamma, T_{1}\right)=A S\left(\gamma, T_{1}\right)-\gamma
$$

then

$$
\begin{aligned}
& \frac{\partial G\left(\gamma, T_{1}\right)}{\partial T_{1}} \\
& \quad=A \frac{\partial S\left(\gamma, T_{1}\right)}{\partial T_{1}} \\
& \quad=-\frac{\alpha A \int_{0}^{\Omega} e^{[\sigma(r-\rho)-\gamma] v} d v}{\int_{0}^{\Omega} e^{[(\sigma-1) r-\sigma \rho] u} d u} \frac{\int_{T_{1}}^{T_{2}}\left[e^{(\gamma-r) u}-e^{(\gamma-r) T_{1}}\right] d u}{\left(T_{2}-T_{1}\right)^{2}} \\
& \quad>0,
\end{aligned}
$$

for $\gamma<r$. So, $T_{1}=\widetilde{T}_{1}(\gamma)$.

At $E_{1}$ in Figure 1, $A\left(\partial S\left(\gamma, T_{1}\right) / \partial \gamma\right)>1$. Hence, $\partial G\left(\gamma, T_{1}\right) /$ $\partial \gamma=A\left(\partial S\left(\gamma, T_{1}\right) / \partial \gamma\right)-1>0$ and

$$
\frac{d \widetilde{T}_{1}}{d \gamma}=-\frac{\partial G\left(\gamma, T_{1}\right) / \partial \gamma}{\partial G\left(\gamma, T_{1}\right) / \partial T_{1}}=\frac{1-A\left[\partial S\left(\gamma, T_{1}\right) / \partial \gamma\right]}{A\left[\partial S\left(\gamma, T_{1}\right) / \partial T_{1}\right]}<0 .
$$

From Corollary $4, \partial T_{1}(\gamma) / \partial \gamma>0$ and we have $T_{1} \rightarrow-\infty$ when $\gamma \rightarrow r-\eta$ and $T_{1} \rightarrow T_{1}-1 / \eta$ when $\gamma \rightarrow r$. Therefore, there exists a unique $\gamma_{1} \in(r-\eta, r)$ such that $T_{1}\left(\gamma_{1}\right)=0$.

Assume that there is $\gamma_{2} \in(r-\eta, r)$, so that $\widetilde{T}_{1}\left(\gamma_{2}\right)=0$ and $\gamma_{1}<\gamma_{2}$ in Lemma 10; then the equations

$$
\begin{aligned}
T_{1} & =T_{2}-\frac{\ln (1+(\gamma-r) / \eta)}{\gamma-r}, \\
\gamma & =A\left[1-\alpha D\left(\gamma, T_{1}\right)\right]
\end{aligned}
$$

have a unique solution, where $0<r-\eta<\gamma<r$ and $T_{2}>1 / \eta$.

Remark 11. Under certain given conditions, the assumption $\gamma_{1}<\gamma_{2}$ holds. For example, when the parameters are taken the values $\alpha=2 / 3, r=0.32, T_{2}=60, \Omega=100, \rho=0.05, \sigma=$ $1, \eta=0.1, \gamma_{1} \approx 0.20$, and $\gamma_{2} \approx 0.26$.

Theorem 12. There is only a pair of individual years of schooling and economic growth rate, such that individual lifetime utility reaches maximum and the economy has balance growth path under some given parameters.

\section{Conclusions}

The relationship between individual years of schooling and economic growth has been inquired in this paper by using an overlapping generation model. From Theorem 1, we see that optimal individual consumption is effected by individual years of schooling: $d T_{1}(\gamma) / d \gamma>0$ (Theorem 3 and Corollary 4). 
Under given individual years of schooling, the total consumption, asset, and capital are aggregated into the production process and condition of having the balance growth is obtained. Theorems 6 and 7 show that there exists a unique balance growth rate.

Theorem 12 implies that the economy has simultaneously optimal years of schooling and economic growth rate, under which all individuals reach lifetime utility maximum and the economy grows on a balance path.

There are several limitations in our paper. Firstly, the uncertain survival schedule is not considered in this paper. Secondly, the individual's age of retirement is fixed. Thirdly, the bequest motives are not put into the model.

\section{Conflict of Interests}

The authors declared that they have no conflict of interests related to this work.

\section{Acknowledgment}

This work is supported by National Natural Science Foundation of China (71271158).

\section{References}

[1] R. J. Barro, "Economic growth in a cross section of countries," Quarterly Journal of Economics, vol. 106, no. 2, pp. 407-443, 1991.

[2] R. J. Barro and I. X. Martin, Economic Growth, McGraw-Hill, New York, NY, USA, 1995.

[3] M. Bils and P. J. Klenow, "Does schooling cause growth or the other way round?” NBER Working Paper 6393, 1997.

[4] H. Connolly and P. Gottschalk, "Differences in wage growth by education level: do less-educated workers gain less from work experience?” IZA WP 2331, IZA, 2006.

[5] J. G. Altonji and R. A. Shakotko, "Do wages rise with job seniority?" Review of Economic Studies, vol. 54, no. 3, pp. 437459, 1987.

[6] J. A. Mincer, Schooling, Experience, and Earnings, National Bureau of Economic Research, New York, NY, USA, 1974.

[7] S. Kalemli-Ozcan, H. E. Ryder, and D. N. Weil, "Mortality decline, human capital investment, and economic growth," Journal of Development Economics, vol. 62, no. 1, pp. 1-23, 2000.

[8] K. Futagami and T. Nakajima, "Population aging and economic growth," Journal of Macroeconomics, vol. 23, no. 1, pp. 31-44, 2001.

[9] O. J. Blanchard, "Debts, deficits, and finite horizons," Journal of Political Economy, vol. 93, pp. 223-247, 1985.

[10] H. d'Albis, "Demographic structure and capital accumulation," Journal of Economic Theory, vol. 132, no. 1, pp. 411-434, 2007.

[11] P. M. Romer, "Increasing returns and long-run growth," Journal of Political Economy, vol. 94, no. 5, pp. 1002-1037, 1986. 


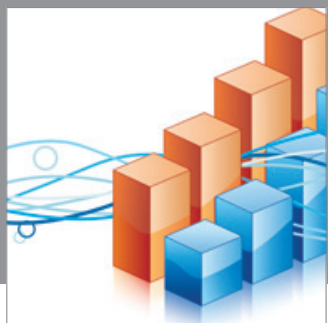

Advances in

Operations Research

mansans

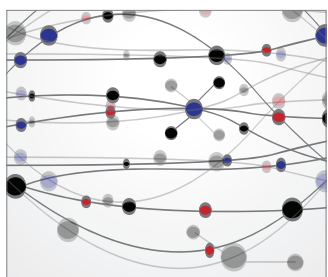

The Scientific World Journal
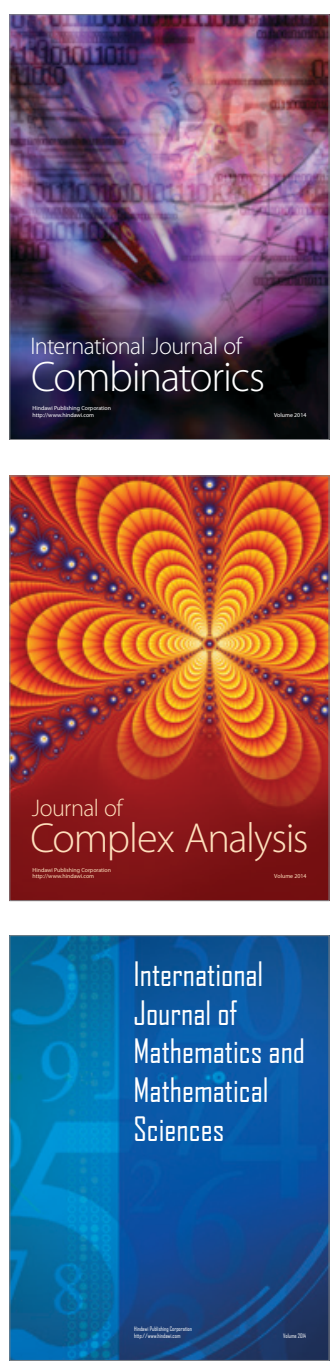
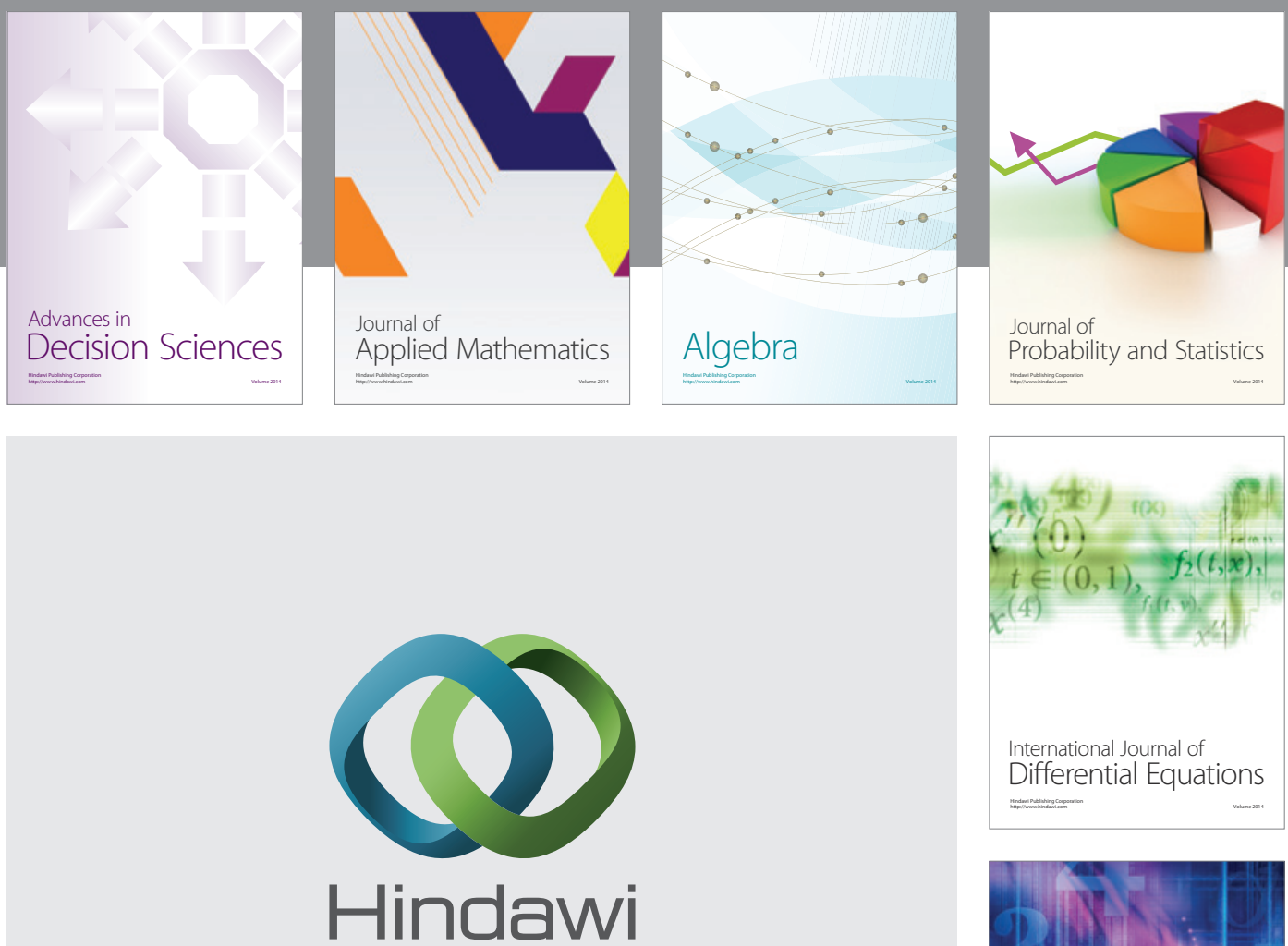

Submit your manuscripts at http://www.hindawi.com
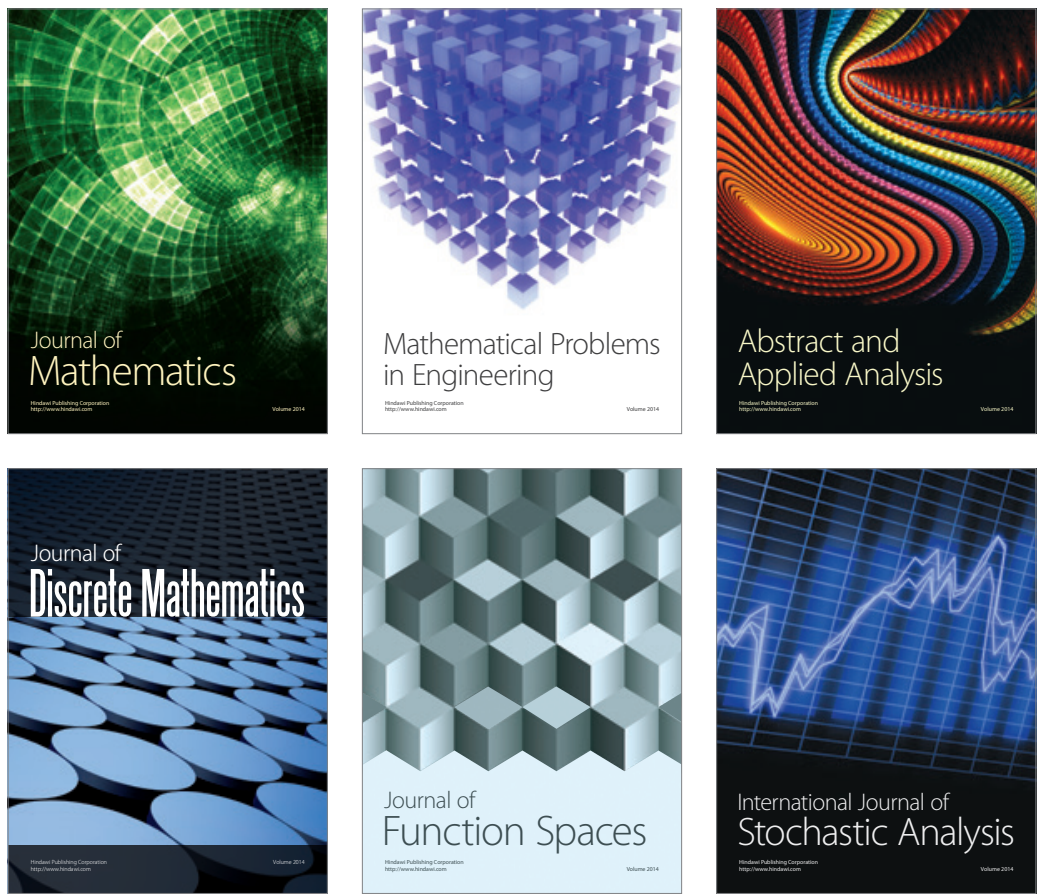

Journal of

Function Spaces

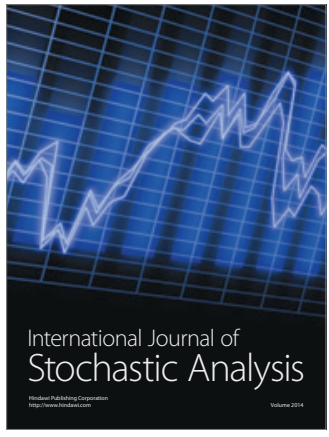

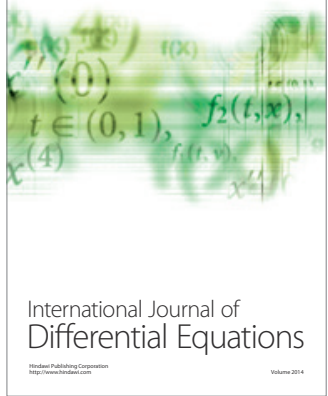
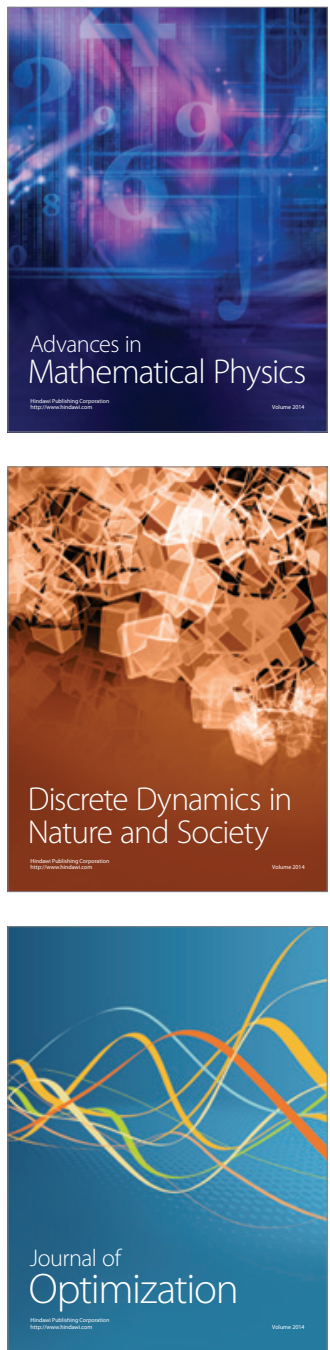